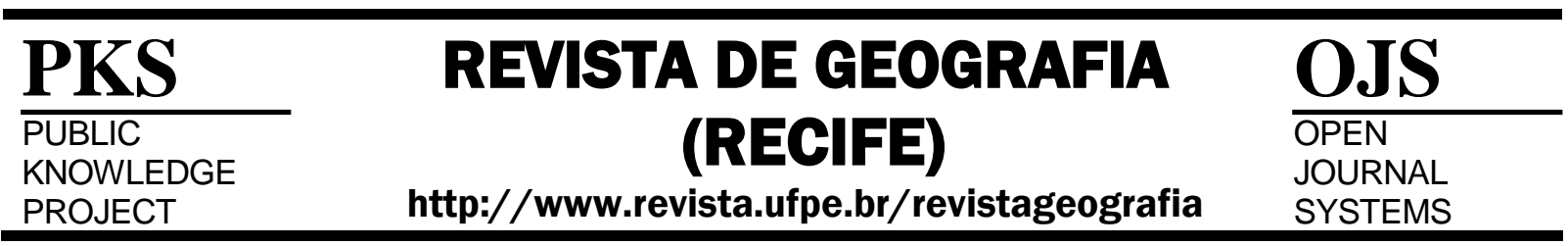

\section{EDUCAÇÃO GEOGRÁFICA E CIBERESPAÇO: CONVERGÊNCIA ENTRE O CONHECIMENTO E AS REDES}

\author{
Francisco Kennedy Silva dos Santos ${ }^{1}$; Mateus Ferreira Santos ${ }^{2}$
}

${ }^{I}$ Professor e pesquisador do Programa de Pos-Graduacao em Geografia da UFPE. Líder do Grupo de Pesquisa Educação Geográfica, Cultura Escolar e Inovação (GPECI/UFPE/CNPQ). Email: kennedyufpe@ gmail.com ${ }^{2}$ Discente de mestrado no Programa de Pós-graduação em Geografia da Universidade Federal de Pernambuco. Colaborador do Grupo de Pesquisa Educação Geográfica, Cultura Escolar e Inovação-GPECI/UFPE. Email: mateusfst@hotmail.com

Artigo recebido em 21/12/2016 e aceito em 30/04/2017

\begin{abstract}
RESUMO:
O presente artigo, de natureza teórica, pretende apresentar alguns apontamentos quanto a educação geográfica e ciberespaço, revelando como esta convergência pode mobilizar saberes e possibilitar a construção de conhecimentos significativos entre professores e alunos em um contexto educacional e tecnológico. O papel revolucionário apresentado pela internet tem criado diferentes percepções nos indivíduos quanto as suas experiências desenvolvidas no cenário-mundo, as redes digitais têm dado voz as pessoas e colaborado para que todos sejam construtores de um novo mundo, nesse caso virtual, sem barreiras geográficas para as relações sociais e o desenvolvimento da intersubjetividade. Neste sentindo é necessário pensar no ensino de geografia que atenda as demandas atuais, refletindo sobre novos métodos que beneficiem o aluno para que se reconheça como agente socialmente crítico e reflexivo que constrói novas espacialidades e transforma outras.
\end{abstract}

Palavras-chave: Redes Digitais, Ciberespaço, Geografia Escolar, Informação, Conhecimento.

\section{GEOGRAPHIC EDUCATION AND CYBERSPACE: CONVERGENCE BETWEEN KNOWLEDGE AND NETWORKS}

\begin{abstract}
:
The present article, of a theoretical nature, intends to present some notes regarding geographic education and cyberspace, revealing how this convergence can mobilize knowledge and enable the construction of significant knowledge among teachers and students in an educational and technological context. The revolutionary role presented by the Internet has created different perceptions in individuals about their experiences developed in the world scenario, digital networks have given voice to people and collaborated so that all are constructors of a new world, in this virtual case, without geographical barriers to social relations and the development of intersubjectivity. In this sense it is necessary to think of the teaching of geography that meets the current demands, reflecting on new methods that benefit the student so that he recognizes himself as a socially critical and reflexive agent that builds new spatialities and transforms others.
\end{abstract}

Keywords: Digital Networks, Cyberspace, School Geography, Information, Knowledge. 


\section{INTRODUÇÃO}

A contemporaneidade nos situa em um contexto de dificuldades e possibilidades quanto ao uso de tecnologias digitais. Com a globalização, novos arranjos técnicos tem se materializado no espaço geográfico e esse espaço também tem se virtualizado, fortalecendo a ideia de conexão em redes ao dualismo que nos aproximam e nos distanciam um dos outros. Para Santos (1996) as redes tem invadido a sociedade como um todo e apresentado inúmeras transformações ao longo dos séculos, principalmente quanto aos fixos e fluxos, já que as acelerações tecnológicas têm potencializado uma grande transformação das informações, transações, comunicações e do conhecimento.

As redes digitais tornam-se geográficas quando a espacializamos. É notório que a apropriação massiva dos meios digitais tem favorecido a transformação intensa das pessoas, possibilitando-as aproximações com o ciberespaço, que é carregado de rapidez e elementos e tem favorecido novas relações com os lugares e com outros indivíduos que estão a quilômetros de distância, mas que por meio de computadores e dispositivos móveis conectados a internet têm estado virtualmente aproximados. O ciberespaço é caracterizado como mais uma espacialidade; configura-se como um espaço virtual formado pela interconexão da rede mundial de computadores. Por meio dele se constrói novos territórios, paisagens, lugares e são desenvolvidos diversos arranjos sociais. Além disso, congrega inúmeras intencionalidades e racionalidades.

Para Santos e Botêlho (2016, p. 6), "entender a sociedade em rede é compreender que o espaço virtual vem contribuindo para suprir as necessidades de indivíduos que utilizam da imaterialidade para realizar atividades que antes exigiriam maior tempo e deslocamento (relação espaço-tempo)".

O desenvolvimento de instrumentos e ferramentas tecnológicas tem permitido que o ciberespaço constitua uma nova realidade não física, não material, mas tão real quanto a material, criando uma nova cultura digital, ou cibercultura, síncronas e assíncronas que mobilizam todo o globo numa grande teia digital.

Nessa direção, compreendemos que esse processo de virtualização e transformação da sociedade têm impactado positivamente a produção e apropriação de conhecimentos, permitindo uma maior divulgação de propostas, experiências e saberes científicos que antes se restringiam a bancos de dados das instituições de ensino e pesquisa. Hoje quase tudo está 
online. A possibilidade que os indivíduos têm em entrar em contato com novas realidades e contextos têm desenvolvido novas capacidades cognitivas e a inteligência coletiva.

$\mathrm{Na}$ educação, diversos questionamentos são postos quanto aos desafios que as tecnologias digitais têm apresentando, sendo enxergadas não só como instrumento técnico que tem facilitado a vida das pessoas, mas como recursos fundamentais que podem ser apropriados e integrados ao processo de ensino e aprendizagem, principalmente porque as redes digitais têm adentrado as instituições de ensino por meio dos dispositivos móveis, portados pelos alunos, despertando diferentes cenários e implicando a mudança no paradigma educacional (MORAN, 2000; KENSKI, 2007).

Diante desse contexto, o presente artigo, de natureza teórica, pretende apresentar alguns apontamentos quanto a educação geográfica e ciberespaço, revelando como esta convergência pode mobilizar saberes e possibilitar a construção de conhecimentos significativos entre professores e alunos em um contexto educacional e tecnológico.

\section{A GEOGRAFIA E O CIBERESPAÇO: LANÇANDO REDES, PESCANDO CONHECIMENTOS}

A apropriação das redes digitais no atual período tem crescido muito, o acesso a diversos serviços, informações e entretenimento tem garantido o surgimento de uma sociedade em redes, modificando comportamentos dos indivíduos que utilizam do virtual para suprir suas diversas necessidades. A internet foi criada como arma para se vencer batalhas no período pós-segunda guerra mundial, a partir dali ela passa a ser instrumento de comunicação, sendo utilizada como meio de trabalho, divulgações de informações, pesquisas, relações sociais, entre outros.

As distâncias que até alguns períodos atrás eram longínquas tem se comprimido, pois com o 'bum' da globalização, surgimento dos espaços virtuais e maiores acesso a informação, as relações de negociação, relações de comunicação e relações pessoas têm acontecido mais rapidamente e com frequências diárias. O Ciberespaço tem sido esse campo virtual capaz de imaterializar diversos serviços e relações possibilitando um maior alcance. Silva e Tancman (1999) afirmam que,

A velocidade dos meios eletrônicos instaura uma nova forma de experienciar o tempo, substituindo a noção de tempo-duração por tempo velocidade e a instantaneidade das relações sociais. O tempo advindo das novas tecnologias 
eletrônico-comunicacionais é marcado pela presentificação, ou seja, pela interatividade on-line, fato constatado nas tecnologias de telepresença em tempo real que alteram nosso sentido cultural de tempo e espaço (SILVA E TANCMAN, 1999, p. 55-56).

Dessa forma, a Geografia tem se apropriado desse espaço navegável e tem tecido diversos significados para incorporação da ciência nesse espaço fluido e veloz. No entanto, Moraes (2013) tem nos alertado que a ciência geográfica ainda apresenta uma teorização bastante tímida a cerca das novas tecnologias virtuais. Ainda são poucos pesquisadores no cenário nacional que tem enfocado seus estudos sobre a análise de como as redes informacionais inserem-se no espaço geográfico. O autor informa ainda que,

Dentro de uma perspectiva mais simplista, costuma-se considerar a Internet e o ciberespaço (o espaço formado pela interconexão da rede mundial computadores) como elementos virtuais. Essa carência de uma materialidade de fixos em detrimento dos fluxos pode explicar por que os geógrafos pouco têm estudado este tema, pois, dentro de uma concepção mais clássica da Geografia, as principais categorias analisadas (como território, lugar, ambiente, região, etc.) partem de uma análise da relação da sociedade como o meio em que vive (MORAES, 2013, p. 139-140).

Tomando como ponto de partida esses apontamentos, as discussões aqui não se restringirão apenas as concepções geográficas, mas será feito uma aproximação entre autores da Geografia e de outras áreas do conhecimento, no intuito de melhor dialogar a respeito do fenômeno que está sendo tratado. Atualmente, o debate a cerca das redes digitais tem sido importante pela necessidade de explicar as diferentes organizações espaciais e sociais quem têm se projetado no cenário mundo. As novas tecnologias tem representado uma era das relações homem - técnica - meio e do conhecimento.

Para Castells (2003, p. 7) as redes são uma prática humana muito antiga, porém elas ganharam vida nos dias atuais devido ao surgimento e aprimoramento da internet. "As redes têm vantagens extraordinárias como ferramentas de organização em virtude de sua flexibilidade e adaptabilidade inerentes, características essenciais para se sobreviver e prosperar num ambiente em rápida mutação".

Um indivíduo conectado a uma rede digital pode adentrar em um espaço virtual veloz, que a todo o momento milhares de transações, informações, vendas e construções, vêm sendo efetivados, demonstrado que essa rede não para e que a cada fluidez ela se aprimora. Como afirma Moraes (2013, p. 142), “o espaço constituído pelas redes incrementadas pela ciência e 
pela tecnologia, portanto, é um espaço de transação, porção da totalidade que, devido a seu conteúdo técnico, permite uma comunicação permanente, precisa e rápida".

Apesar de haver críticas com relação a apropriação massiva das redes virtuais pelos indivíduos que tem mudado hábitos e projetados novas relações sociais, é possível perceber que o ciberespaço tem contribuído para suprir as necessidades de indivíduos que utiliza da imaterialidade para realizar atividades que antes, sem ele, exigia mais tempo e deslocamento. Lemos (2007, p. 16) salienta que "uma das características da sociedade contemporânea diz respeito ao fato de que as organizações sociais e instituições de todos os tipos (comerciais, educacionais, jurídicas, financeiras, políticas, etc.) têm, agora, extensões no ciberespaço".

As novas tecnologias em redes têm favorecido diversos setores que utilizam dos mesmos espaços fluidos para a realização de atividades que muitas vezes demandavam mais tempo e custos. Além disso, trabalhar com redes digitais, é trabalhar com a ideia articulada de informação. A rapidez e objetividade com que as informações são passadas e chegam até os indivíduos é um grande diferencial no que se diz respeito aos aparelhos tecnológicos que conecta usuários em diferentes lugares.

No atual período informacional, as tecnologias digitais têm ganhado novos sentidos, principalmente com os avançados recursos computacionais e de internet, remetendo-se a ideia de que o espaço tem alargado e o tempo vem sendo comprimido (SANTOS, 1994). Esse espaço virtual, denominado também de ciberespaço, vem sendo bastante discutido e se consolidando rapidamente, impulsionado principalmente pela necessidade de tecer bases conceituais que expliquem como essa estrutura de redes, através da internet, afeta e é influenciada pela dinâmica territorial.

O ciberespaço é um ambiente virtual criado a partir das conexões dos nós que representam a internet, espaço navegável. Para Lévy (1999, p. 32) é o "novo espaço de comunicação, sociabilidade, de organização e de transação, mas também novo mercado da informação e do conhecimento". Já para Lemos (2002, p. 146, 148),

O ciberespaço é um ambiente mediático, como uma incubadora de ferramentas de comunicação, [...] conectando pontos ordinários, criando territorialização e desterritorialização sucessivas. [...] formando comunidades ordinárias. É um espaço (relacional) de comunhão, colocando em contato, através do uso de técnicas de computação eletrônica, pessoas do mundo todo. [...] Mais do que um fenômeno técnico, o ciberespaço é um fenômeno social. 
Apresentar uma conceituação precisa do que venha ser o ciberespaço ainda não é uma tarefa fácil, principalmente porque os seus atributos designados é o virtual, é um espaço desterritorializado, por isso é necessário buscar os sentidos que estão por trás do simples significado da palavra, já que o espaço móvel, virtual, navegável, se faz e refaz em questão de segundos e possui uma utilidade muito importante nos dias atuais.

O Ciberespaço existe em um local indefinido. Ele é real, porém a sua materialidade não pode ser percebida, porque ele existe independente de se estar online ou não, ou seja, em qualquer lugar que um computador conectado a internet for desligado o ciberespaço não deixa de existir, ele possui uma lógica virtual que independe de atores específicos. Dessa forma, não podemos imaginar que essa rede virtual pode se restringir apenas a acontecimentos ou ser fruto de uma manipulação especifica, pois ele tem um caráter fluido que o torna virtual.

O proposito aqui não é afirmar que a as redes digitais agem sozinhas, nem tão pouco dizer que elas independem do humano. Mas elas avançaram tanto, atingiram proporções mundiais inimagináveis que é difícil cogitar que elas possam deixar de existir um dia, ou até mesmo que elas possam ser fruto de uma única manipulação, pois como se sabe, cada individuo que adentra a uma rede virtual tem uma suposta liberdade para realizar o que deseja, se conectar quanto tempo quiser e difundir ainda bem as potencialidades que esse recurso pode oferecer. Batty (2003, p. 144) alerta que,

O ciberespaço difere de ciberlugar no sentido de que os espaços criados não mapeiam qualquer relação individual em lugares reais, mas o ciberespaço não está necessariamente no espaço imaginado - é suficientemente real, é o espaço instalado por aqueles que usam computadores distantes para se comunicar.

Assim, ele pode ser concebido também como uma convergência digital, que consiste em um agrupamento de mídias como telefone, computador, televisão, livro digital, entre outros, que passam a ter uma transmissão de conteúdo integrado a um único dispositivo, tendo a internet como um suporte para essa convergência.

Se o ciberespaço é um ambiente virtual muito importante para sociedade contemporânea, é papel da Geografia enquanto ciência buscar compreender os seus avanços enquanto materialização da sociedade capitalista, visto que, o ciberespaço é apoiado nas forças do capitalismo que busca aumentar incessantemente a circulação de capital, mercadorias e serviços numa escala planetária (LEMOS, 2002). Para que isso continue acontecendo, vários investimentos e pesquisas são direcionados ao aprimoramento das redes, 
ou mais especificamente as tecnologias informacionais. Tal feito tem produzido uma sociedade também virtual, diminuído as relações físicas uns com os outros.

Salientando as relações virtuais e presenciais, Lévy (1996, p.16) aponta que "o virtual não se opõe ao real e sua efetivação material, mas sim ao atual". O virtual é uma extensão do real, pois as suas representações traduzem o real. À guisa de exemplificação, mesmo que um usuário conectado a uma rede social crie e utilize um perfil falso, esse feito não deixa de ser real porque existe um individuo por trás manipulando essa rede. Assim, observa-se que o homem não é e nunca será indispensável para que as transações virtuais aconteçam. Apresentando ainda as ideias de Silva e Tancman (1999, p. 55-56),

O ciberespaço é, então, um ambiente que permite inúmeras possibilidades do mundo real. $\mathrm{O}$ mundo virtual caracteriza-se não propriamente pela representação, mas pela simulação. Esta simulação é, na verdade, apenas uma das possibilidades do exercício do real. Desse modo, podemos afirmar que o ciberespaço não está desconectado da realidade.

O ciberespaço nos faz desconhecer os caminhos que as informações, transações e relações sociais percorrem. Os provedores de acesso são muitos, o que indefine os roteiros que os acontecimentos virtuais se realizam, só sabemos que tais dados chegaram em questão de segundos em uma dada conta de perfil, mas não sabemos por onde percorreu, se desviou caminhos, se passeou por outros países. As referências de paisagem percebida, lugar como conjugação da horizontalidade e da verticalidade (SANTOS, 1996) e ou como espaço vivido (TUAN, 1983) desaparecem, visto que, a imaterialidade mesmo sendo real não traduz todas as dinâmicas que o espaço material apresenta.

No entanto, o ciberespaço pode apresentar um lugar na rede, ou "lugar virtual" como é definido por Silva e Tancman (1999), pois nas redes é possível uma relação de convivência entre pessoas ligadas por afinidades que produzem identidades impressas nos grupos virtuais. Temos aí um novo espaço vivido enquanto produto das relações sociais, impondo novas formas de pertencimento diferentes da materialidade dos lugares. Logo, o individuo por trás de um aparelho digital com acesso a internet, pode se pertencer a um lugar individual, simulacro, que para outros usuários não existe.

Entender as organizações que ocorrem no ciberespaço e seus efeitos reais na sociedade está longe de ser totalmente compreendido pela ciência geografia, pois as suas dinâmicas e mutações são bem variadas e rápidas. O dinamismo que as redes apresentam como a disponibilidade de informações e serviços, acaba sufocando diversos conteúdos. A 
todo o instante informações são passadas, relações criadas e desfeitas e novos caminhos são percorridos demonstrando o quanto as redes digitais estão vivas e potencializam mudanças de comportamentos.

O mundo virtual move novos paradigmas, o conhecimento torna-se recurso principal das grandes potências desenvolvidas. Qual geografia “emergente” será capaz de compreender e traduzir os fenômenos espaciais que estão ocorrendo nessa nova sociedade? Quando a ciência geográfica dará conta de explicar as transformações espaciais matérias imbricadas nas imateriais? Esses questionamentos e outros são necessários serem feitos na busca de entender a atual sociedade movida pela globalização, conectada em todas as suas dimensões por diferentes redes, que seguem lógicas de produção e consumo cada vez maior.

O ciberespaço também é dotado de funcionalidades e temporalidades, expressam características movidas pela celeridade das informações hipertextuais. A ausência de espaçotempo rígido é suplantada por nodosidade de informações que podem ser tornar conhecimento. Lévy (1997) considera que,

O espaço do novo nomadismo não é o território geográfico nem o das instituições ou dos Estados, mas um espaço invisível dos conhecimentos, dos saberes, das forças de pensamento no seio da qual se manifestam e se alteram as qualidades do ser, os modos de fazer sociedade. Não os organismos do poder, nem as fronteiras disciplinares, nem as estatísticas dos mercados, mas sim o espaço qualitativo, dinâmico, vivo, da humanidade que se inventa ao mesmo tempo que produz o seu mundo (p.17).

Desse movimento surgem territórios cognitivos, diferentes identidades e sujeitos que expressam o seu ponto de vista ou se utilizam do virtual para o favorecimento de suas lutas apenas ligando o computador conectado a internet. Regras quanto a troca de informações, envio de arquivos e atualização de status pessoais tende a não existir, pois as redes virtuais dá autonomia para que indivíduos, organizações, empresa e Estado, adentrem ao espaço cibernético de qualquer parte do mundo e a qualquer hora, dentro das possibilidades de cada localidade.

Reconhecendo as implicações dessa nova era da informação e comunicação, faz-se necessário investigar como a construção e apropriação de conhecimentos têm sido efetivadas nesse celeiro de mudanças e mutações. Grupos acadêmicos, escolares e outras instituições de ensino têm sido cobrados quanto a sua inserção nesse mundo virtual para a produção de conhecimento e instrumentalização dos seus espaços. 
Mas é preciso ter cautela quando se fala em redes, conhecimento, produção e reprodução dos mesmos, principalmente na ciência, já que muitos conteúdos disponíveis na rede não têm garantia de veracidade, algumas pesquisas e notícias divulgadas ainda estão por trás do anonimato. Porém, mesmo com milhares de conteúdos impróprios ou não verídicos sendo vinculado, o ciberespaço apresenta-se como um espaço de construção de conhecimentos científicos e troca de experiências que tem contribuído ainda mais no avanço da ciência.

A educação tem se apropriado dos aparatos técnicos e da própria rede e seus conteúdos para a produção e difusão de conhecimentos que antes se limitavam a livros de acervos e bibliotecas ou aos centros de pesquisa (MORAN, 2000; KENSKI, 2007). Os ambientes virtuais (como bibliotecas online, redes sociais, sites, blogs, plataformas online, e outros.) têm favorecido a difusão de novas descobertas que não se restringe a somente uma localidade. $O$ conhecimento tem se tornando um produto globalizado (SANTOS, 1996; KENSKI, 2007), com esse feito milhares de descobertas, experimentos, questionamentos e respostas são disseminados a todo o momento na internet e milhares de pessoas têm utilizado desse objeto técnico para o desenvolvimento de aprendizagens.

O ciberespaço tem sido mais um espaço para a construção de saberes, os quais perpassam diferentes escalas institucionais, sejam os grandes centros de pesquisa e universidades como escolas técnicas e de formação básica. Os limites impostos nessa escala são dados pelo acesso, em que a única dificuldade encontrada atualmente para a falta de informação e conhecimentos atualizados é o não acesso ou a inoperância de alguns órgãos governamentais na disponibilização de estruturas ou equipamentos para que os indivíduos naveguem e se apoderem desse novo fenômeno.

Os desafios impostos às instituições de ensino são muito grandes, porém não os impedem que sejam capazes de desenvolver nos estudantes, profissionais e pesquisadores competências para participar e interagir com o mundo global, alertá-los que a aprendizagem não é um processo estático, mas que estará em constante mutação, afirmação e negação durante toda a história humana.

Com relação ao ensino de geografia, foco principalmente desse trabalho como um todo, ele deve ter como proposito pensar a organização dos sujeitos frente às diversas transformações dessa nova sociedade em redes. Entender o ciberespaço como uma nova subcategoria a ser estudada também é de fundamental importância, já que as instituições de 
ensino não devem ficar de fora das transformações e tendências que a sociedade contemporânea tem apresentado.

Posto isso, o ciberespaço constitui-se em um espaço de práticas sociais em que não exclui práticas antigas, mas contribui para o surgimento de novas dinâmicas, territorialidades e identidades, nesse caso o virtual que não deixa de ser real. O mesmo colabora para o surgimento da dialógica complementaridade, ou seja, uma escola virtual que venha colaborar com a escola física, a cidade digital que apresenta outras funcionalidades, mas que colabora na gestão administrativa da cidade física, o modelo de organização do território que não deixa de ser real, no entanto apresenta outras configurações e dimensões no território virtual. Dessa forma, o ciberespaço pode apresentar uma nova forma de democratização dos espaços (virtuais e físicos), restando à ciência geográfica estudá-lo cada vez mais e buscar respostas quanto à organização da atual sociedade conectada.

\section{A CIBERgEOGRAFIA ENQUANTO LÓCUS PARA A APRENDIZAGEM GEOGRÁFICA}

O papel revolucionário apresentado pela internet tem criado diferentes percepções nos indivíduos quanto as suas experiências desenvolvidas no cenário-mundo, as redes digitais têm dado voz as pessoas e colaborado para que todos sejam construtores de um novo mundo, nesse caso virtual, sem barreiras geográficas para as relações e o desenvolvimento da intersubjetividade. Permitir que aprendizes contribuam com habilidades ou adquiram novas habilidades é crucial nesse contexto, principalmente superando obsoletas posturas e práticas que não sincronizam com demandas e realidades atuais.

A educação, a informação e a comunicação são necessidades que prevalecem em todas as relações humanas e técnicas, desta feita, a escola torna-se um espaço fundamental para alimentar essa relação cíclica, assumindo o papel de formar cidadãos para que saibam compreender as complexidades do mundo e os desafios que ele propõe (KENSKI, 2007). Cabe a escola garantir a formação de novas habilidades, atitudes e valores para que os indivíduos saibam viver e conviver em uma sociedade em constante transformação.

O mundo tem mudado numa velocidade muita rápida, no entanto, a escola ainda vem seguindo passos mais lentos e tem encontrado inúmeras dificuldades para a promoção de um ensino que atenda a sociedade contemporânea denominada como tecnológica (LIBÂNEO, 2000). 
O professor de geografia nesse cenário se depara com enormes desafios quanto o chão da sala de aula. Os alunos de hoje não são os mesmos de décadas atrás, isso tem sido bastante positivo, porém, os métodos que muitos docentes têm utilizado para a aprendizagem geográfica ainda permanecem no campo da teorização e descrição. Atualmente os alunos são proativos, desenvolvidos tecnologicamente e possuem o 'mundo' na palma das mãos (por meio dos smartphones e tablets). Santaella (2003) reconhece que atualmente há uma multiplicidade de leitores fora e além do livro.

Dessa forma, pensar no ensino de geografia que atenda as demandas atuais é refletir sobre novos métodos que devem beneficiar o aluno para que ele se reconheça como agente socialmente crítico e reflexivo que constrói novas espacialidades e transforma outras. Pretto (2011, p. 96) tem discutido que "vivemos em um mundo onde as grandes velocidades e, principalmente, a aceleração com que os aparatos se deslocam, provocam modificações profundas nas nossas formas de pensar e de ser".

O professor de geografia precisa refletir sobre a sua prática dentro do contexto da cibergeografia, enxergado os aparelhos digitais para além de um objeto técnico, mas como um aliado para produção de conhecimentos e troca mútua de aprendizagens. O aluno contribui para que o professor tenha familiaridade com os dispositivos digitais, caso não tenha, e o professor favorece o aluno no exercício do pensar e do desenvolvimento intelectual. Moreira e Ulhôa (2009) salientam que,

[...] ensinar Geografia tem se tornado um desafio cada vez maior, pois além de dominar os conhecimentos relativos aos conceitos/categorias inerentes ao ensino dessa disciplina, exige-se que os professores saibam selecionar e utilizar linguagens adequadas para cada situação de ensino-aprendizagem (p. 72).

Esses desafios estão longe de serem superados, porém muito já vem sendo feito, principalmente as novas percepções quanto ao ensino de geografia e as contribuições de pesquisadores que tem motivado professores, cursos formadores e até mesmo o aluno a enxergar o ensino como um processo que pode ser desenvolvido atendendo as inúmeras especificidades dos agentes que integram a escola. Para Guimarães (2000, p. 22), “[...] ensinar e aprender Geografia tem significado pensar um novo processo, com possibilidades múltiplas que poder caminhar para expectativas, resistências e ainda fé exagerada nos caminhos que se projetam". 
Consideramos que a Geografia escolar vem tomando novos rumos nos últimos anos, tanto pela necessidade de ressignificação de suas abordagens e conceitos, quanto pelas reformulações dos seus cursos de licenciatura em que a centralidade não é mais o estudo dos conteúdos a serem ensinados - o currículo teve uma maior abertura para as disciplinas pedagógicas -, mas o papel do professor e do aluno na escola e as relações que esses indivíduos devem desenvolver com o meio (VESENTINI, 2003).

As abordagens quanto às práticas de ensino também têm mudando bastante o seu foco, que antes se tratava da memorização de conteúdos, descrição dos objetos técnicos e naturais contidos no espaço, para uma postura mais crítica e intuitiva a respeito das novas relações que a sociedade vem desenvolvendo com o meio e suas repercussões do micro à macro escalas. Não que as velhas práticas têm sido extintas, mas surgiram novos olhares e rotas para o ensino participativo e contributivo para o dia a dia dos seus aprendizes.

O ensino calcado numa pratica pedagógica tradicional, moderna e tecnicista é bastante criticado e considerado obsoleto, dando lugar a uma pratica motivada por um ensino inventivo, participativo e colaborativo, em que as diversas habilidades e experiências devem ser privilegiadas e os conteúdos trabalhados precisam ter maiores aproximações com o cotidiano dos indivíduos que são submetidos ao processo de aprendizagem. $\mathrm{O}$ aluno deve adquirir novas visões com relação ao espaço, exercendo a criticidade e se enxergando como um agente social importante como qualquer outro.

Nessa direção, Cavalcanti (1998) apresenta que o ensino da Geografia deve proporcionar ao aluno a compreensão do espaço geográfico na sua concretude e contradições. E para que este contribua para a formação de cidadãos críticos e participativos, é necessário que o professor se proponha a trabalhar em sala de aula com conteúdos críticos baseados em determinados fundamentos metodológicos dessa ciência. Todavia, não só trabalhar com conteúdos específicos, mas criar ambientes favoráveis para que os próprios alunos se reconheçam como participantes e transformadores da sociedade, atingindo a criticidade. É fundamental manter uma relação entre conteúdo e método. De acordo com Moraes (2013),

[...] É mister gerar um esforço de traduzir pedagogicamente as novas propostas e os novos discursos desenvolvidos pela Geografia [...] Aproximar teoria e prática no plano do ensino de Geografia, estimulando uma reflexão pedagógica que assimile os avanços teóricos da Geografia nas últimas décadas (p. 122). 
Vesentini (2003) salienta que numa proposta geográfica de ensino crítico é necessário ir além dos conteúdos propostos.

Um ensino crítico de geografia não consiste pura e simplesmente em reproduzir num outro nível de conteúdo da(s) geografia(s) crítica(s) acadêmica(s); pelo contrário, o conhecimento acadêmico (ou científico) deve ser reatualizado, reelaborado em função da realidade do aluno e do seu meio [...]. Não se trata nem de partir do nada e nem simplesmente aplicar no ensino o saber científico; deve haver uma relação dialética entre saber e a realidade do aluno - daí o professor não ser um mero reprodutor, mas um criador (p.78).

Além disso, reconhecer a escola com um palco de aprendizagens em que ocorre a troca de ideias e conhecimento é necessário, mas limitá-lo como o único local favorável para a construção de conhecimento é uma concepção errônea que ainda é concebida por muitos professores e gestores escolares. As redes digitais e sociais tem se revelado como novos espaços informais de produção de conhecimento e desenvolvimento de habilidades.

Para a construção de um ensino de geografia dinâmico e participativo é preciso romper com ideia do professor como detentor do conhecimento e voltar os olhos para novas concepções que privilegiam a produção saberes individuais e coletivos. As dinâmicas espaciais têm extrapolado limites físicos e configurado nossos espaços virtuais de produção e consumo.

Faz-se necessário a busca incessante por novas alternativas de se entender o espaço geográfico e as relações que a sociedade desempenha nele, percebendo que a lógica do aprender não se faz somente por meio do estudo de teorias e conceitos, mas com as práticas cotidianas e por meio de relações sociais que os indivíduos desenvolvem, mesmo estando distante fisicamente. A lógica do virtual tem garantido isso.

É interessante pensar como o mundo tem se transformado de forma intensa, o acesso a informação é imediata e o conhecimento sofre mutações tão rápidas quanto essas mudanças. O paradigma da modernidade não consegue mais dar respostas a todas essas demandas, necessitando de um novo paradigma que atenda as complexidades e as fragilidades da atualidade, tanto na escola quanto na sociedade como todo.

Qualquer tentativa de se construir ou adotar um novo modelo de ensino que vise uma transição de paradigmas entre o ensino tradicional e tecnicista para outro inovador é algo trabalhoso que exige do professor da educação básica conhecimentos, habilidades e um ambiente propício para tal feito, principalmente porque para que isso ocorra não são só necessários saberes pedagógicos, mas estruturas adequadas para o desenvolvimento de um

$\begin{array}{lll}\text { Santos e Santos, } 2017 & \text { ISSN 0104-5490 }\end{array}$


bom trabalho. Todavia não podemos esquecer que os alunos são sujeitos ativos na apropriação e manipulação do ciberespaço, muitos são dotados de habilidades e dão distintos significados as redes, as quais se fazem e refazem em diversos lugares. Lévy (1999, p. 181), explicita que,

Aprendizagens permanentes e personalizadas através de navegação, orientação dos estudantes em um espaço de saber flutuante e destotalizado, aprendizagens cooperativas, inteligência coletiva no centro das comunidades virtuais, desregulamentação parcial dos modos de reconhecimento dos saberes, gerenciamento dinâmico das competências em tempo real... esses processos sociais atualizam a nova relação com o saber .

Os saberes adquiridos por meio do ciberespaço exige uma atitude multissensorial dos envolvidos, pois nega a técnica enquanto lócus principal da aprendizagem, concebendo-a como meio para o fortalecimento de uma postura coordenada e não estratégica, portanto, o ensino de geografia apoiado nas redes digitais deve ser considerado um meio vital para a reflexividade e intersubjetividade entre professores e alunos. A cibergeografia ou ciberespaço deve ser caracterizado como plano de fundo para a construção de conhecimentos, já o ensino de Geografia como um caminho que pode levar os alunos por meio de suas contribuições ao desenvolvimento cognitivo e a aprendizagem como resultado final desse processo a ser significado e socializado.

Partindo dessa reflexão, precisamos reconhecer quais métodos e metodologias podem ser desenvolvidas no ciberespaço. Daí volta-se ao tratamento do ensino participativo e colaborativo como oportuno à construção de saberes. Umas das ferramentas bastante utilizadas por professores e alunos tanto para comunicação e entretenimento como no ensinar e aprender geografia são as redes sociais (TONETTO e TONINI, 2015). As discussões sobre as potencialidades/operacionalidades das práticas pedagógicas da Geografia na apropriação das redes sociais têm ganhado grandes destaques na literatura, tanto pelo avanço dos debates sobre novos caminhos que podem levar a ressignificação do ensino de geografia, como pelas práticas exitosas evidenciadas em artigos de congressos e periódicos. É importante destacar que,

A utilização de Tecnologias da Informação e Comunicação (TIC) na educação está crescendo nos últimos anos e a distribuição de dispositivos móveis como tablets e computadores portáteis nas escolas públicas, pode ter nessas mídias, uma aliança entre a estratégia pedagógica desenvolvida pelos professores e a mobilização espontânea dos discentes nesses espaços, o que pode ser um facilitador do trabalho pedagógico (ALENCAR; MOURA; BITENCOURT, 2013, p. 87). 
Indo nessa direção, o Facebook é um grande exemplo de como os espaços virtuais sociais tem contribuído na dinamização de novas práticas e fortalecimento do processo de ensino e aprendizagem. A comunicação e entretenimento não são mais as únicas funções dessa rede social, principalmente quando é adotada a favor do conhecimento. A interatividade que a mesma proporciona também tem condicionado o amadurecimento de discussões e debates a respeito de diversos assuntos de cunho social, contribuindo para despertar nos usuários uma visão mais crítica quanto às questões sociais, politicas e econômicas.

Alencar, Moura e Bitencourt (2013) salientam que,

O Facebook, mídia social capitaneada por Mark Zuckeberg em 2004, que tem como objetivo a interação de pessoas e compartilhamento de informações e imagens, é uma das mais usadas e já foi ponto de encontro para grandes manifestos como o "Un millón de voces contra las FARC". Tal manifesto, nos mostra que as redes sociais não servem somente para o entretenimento, podendo assim contribuir para melhores condições de acesso à informação, educação, à intervenção social e política, entre outras dimensões que englobam a cidadania (p.87).

Elucidando ainda mais as características que essa rede social pode apresentar para o processo de obtenção do conhecimento e o desenvolvimento colaborativo de aprendizagens é a criação de grupos online, de acesso público ou privado, que visem a discussão de temáticas e conteúdos trabalhados em sala de aula, como também a produção coletiva de tarefas e realização de atividades (como postagens de informações sobre o que é desenvolvido na escola, trabalhos amostrais e experiência didática), servindo como um modelo a ser adotado para a criação de novas experiências em outras escolas, além de fóruns e debates que envolvam professores e alunos na discussão de assuntos no que diz respeito ao chão da sala de aula e as práticas exercidas na comunidade que os mesmos estão inseridos.

É necessário aguçar nos alunos a vontade de estudar e compreender a geografia nos diversos espaços sendo eles virtuais ou materiais, pois as dinâmicas que ocorrem no ciberespaço são totalmente diferentes das que acontecem nas escalas materiais, porém uma completa a outra e hoje são pertinentes para a compreensão do lugar, do território, da paisagem e das redes que os indivíduos constroem.

Os professores de geografia precisam favorecer que os seus alunos compreendam os processos sociais e as crises que a sociedade vem e tem enfrentado, enxergando o ciberespaço como um meio difusor de informações e conflitos ideológicos (GOMEZ, 2004). Alertando-os também que as transformações tecnológicas têm mudado hábitos, mas a escola não tem 
mudado na mesma proporção, a classes minoritárias não tem atingindo massivamente a capacidade de pensar como outros sujeitos que dispõem das diversas ferramentas online.

A ciência geográfica tem tentado discutir o papel do ciberespaço na educação, mas muito deve ser feito para incorporá-lo nas novas práticas executadas na sala de aula, seja no estudo das dinâmicas naturais, como nas sociais. Antigas práticas devem ser revistas no sentindo de dar significados aos alunos que utilizam as redes sociais ou qualquer outro ambiente virtual em prol da aprendizagem. Agir colaborativamente pode ser uma alternativa viável dentro de um novo paradigma de ensino emergente, intuitivo e desprendido da concepção de detentores do conhecimento e conteudistas (TORRES E IRALA, 2014).

É preciso instigar dos alunos o que eles tem a contribuir a respeito das questões geográficas, motivá-los a reconhecer nas mídias digitais uma ferramenta favorável para a construção de saberes que não pertencerá só a ele, mas a um coletivo que também tem a somar com novas concepções a respeito do que é trabalhado na escola, entendendo que a construção coletiva além de favorecer a interatividade e o respeito entre aprendizes, pode contribuir para o entendimento das questões locais e solucionar problemas.

Portanto, vivemos em novos tempos, novas roldanas, ressignificar o papel da utilização dos dispositivos virtuais, vendo-o para além de um recurso ou um substituto do docente e da escola, mas um aliado na construção de conhecimentos socialmente relevantes. O saber não está alicerçado apenas nas experiências do espaço material vivido, mas também nas experiências do espaço virtual.

\section{APONTAMENTOS FINAIS}

O ciberespaço tem sido um ambiente virtual capaz de desestabilizar as estruturas físicas e hierárquicas quanto à produção do conhecimento. $\mathrm{O}$ imperativo é fazer com que os sujeitos não se percam nesse espaço virtual e esqueçam o espaço material, em que as relações com as histórias de vida e a cultura se fortalecem. Todavia, as redes têm auxiliado na fortificação dos elementos culturais e de sociabilidade dos indivíduos, favorecendo intercâmbios, espaço de diálogo e de afirmação.

A escola é o ambiente ideal para que a sociabilidade real e virtual possa confluir de maneira dialógica. Ou seja, o aluno vive os componentes culturais, históricos, sociais, econômicos e ambientais de seu espaço/lugar, mas busca no virtual a afirmação destes 
elementos, tornando-se consciente de que estes espaços se atrelam e ambos fortalecem sua subjetividade e leitura do mundo.

Muitas escolas ainda são ambientes de dispersão. A rede é um dos meios pelo qual esse movimento de diáspora de conhecimentos atinge a afirmação do aluno como sujeito social, consciente e capaz de lidar com a realidade de uma sociedade dinâmica, ao mesmo tempo em que se identifica com ela e nela atua. Por meio do ambiente virtual ele pode dialogar e encontrar elementos que o conduzam a consciência de sua existência e nele encontrar percursos para chegar ao entendimento de sua condição de cidadão.

Isso tem a contribuir na sua afirmação como individuo, mas não esqueçamos que é uma rede e a rede implica coletividade, conexão. Essa coletividade também faz menção a sua afirmação, como o saber ouvir e saber responder, visto que, o ciberespaço tem se humanizado bastante, principalmente por ser usado para a socialização de práticas, legitimar discursos, mobilizar ações, e o aluno é capaz de dar sentido a ele quando é conduzido a perceber a internet como um recurso que lhe dá cabimento a pensar multidimensionalmente o mundo.

\section{REFERÊNCIAS}

ALENCAR, G. A.; MOURA, M. R.; BITENCOURT, R. B. Facebook como plataforma de ensino/aprendizagem: o que dizem os professores e alunos do IFSertão - PE. Educação, Formação \& Tecnologias. 6 (1), 86-93, Jul. 2013.

BATTY, M. Geografia Virtual. Geografia - Volume 12 - Número 1 - Jan/Jun. 2003.

CASTELLS, M. A galáxia da internet: reflexões sobre a internet, os negócios e a sociedade; tradução Maria Luiza X de A. Borges, Rio de Janeiro: Jorge Zahar, 2003.

CAVALCANTI, L. S. Geografia, escola e construção de conhecimentos. 13. ed. Campinas: Papirus, 2008.

GOMEZ, M. V. Educação em Rede: Uma visão emancipadora. São Paulo: Cortez: Instituto Paulo Freire, 2004.

GUIMARÃES, I. V. Ensinar e aprender geografia: contexto e perspectiva de professores e alunos como sujeitos sócio-culturais. Rev. Olhares e Trilhas, v. 1, n.1. jan./dez, 2000.

KENSK, V. Educação e tecnologias: o novo ritmo da informação. 3. ed. Campinas, SP: Papirus, 2007.

LEMOS, A. Cidade digital: portais, inclusão e redes no Brasil. Salvador: EDUFBA, 2007. 
2002.

Cultura das Redes: Ciberensaios para o século XXI. Salvador: Editora UFBA,

LÉVY, P. A inteligência coletiva: por uma antropologia do ciberespaço. 3. ed. São Paulo: Loyola, 1997

LÉVY, P. Cibercultura. São Paulo, Editora 34, 1999.

O que é virtual? São Paulo: Ed. 34, 1996.

LIBÂNEO, J. C. Adeus professor, adeus professora?: novas exigências educacionais e profissão docente. 4. ed. São Paulo: Cortez, 2000.

MORAES, F. D. Ciberespaço entre as redes e o espaço geográfico: algumas considerações teóricas. Revista Caminhos de Geografia. V 14, n. 47, Uberlândia, p. 139-149, Set/2013.

MORAN, J. M. Novas Tecnologias e medicação pedagógica. Campinha, SP: Papirus, 2000.

MOREIRA, S. A. G.; ULHÔA, L. M. Ensino em geografia: desafios à prática docente na atualidade. Revista da Católica, Uberlândia, v. 1, n. 2, p. 69-80, 2009.

PRETTO, N. L. O desafio de educar na era digital: educações. Revista Portuguesa de Educação, no 24(1), p. 95-118, 2011.

SANTAELLA, L. Da cultura das mídias à cibercultura: o advento do pós humano. Revista FAMECOS, Porto Alegre, $n^{\circ}$ 22, p. 23-32, dez. 2003.

SANTOS, F. S.; BOTÊLHO L. A. V. As redes digitais como contribuição para a aprendizagem geográfica: mediação, mobilização e interatividade. Revista de Ensino de Geografia, Uberlândia, v. 7, n. 12, p. 4-16, jan./jun. 2016.

SANTOS, M. A Natureza do Espaço: Técnica e Tempo. Razão e Emoção. São Paulo: Hucitec, 1996.

Técnica Espaço Tempo: globalização e meio técnico-científico informacional. $2^{\circ}$ ed. São Paulo: Hucitec, 1994.

SILVA, C. A. F.; TANCMAN, M. A dimensão Socioespacial do Ciberespaço: uma nota. GEOgraphia. Ano, nº2, 1999.

TONETTO, E. P.; TONINI, I. M. Ensinar e aprender geografia com/nas redes sociais. Giramundo, Rio De Janeiro, V.2, N. 3, p. 87-96, jan./jun. 2015.

TORRES, P. L.; IRALA, E. A. F. Aprendizagem Colaborativa: Teoria e Prática. In: TORRES, P. L. (Org.). Complexidade: Redes e Conexões na Produção do Conhecimento.

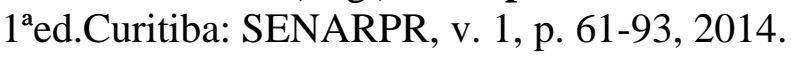

TUAN, Y.F. Espaço e Lugar. São Paulo: Difel, 1983. 
VISENTINI, J. W. Educação e ensino da geografia: instrumento de mediação e/ou de libertação. In: CARLOS, A. F. A. A geografia na sala de aula. $8^{\text {a }}$ Ed. São Paulo: Contexto, p. 14-33, 2010. 